\title{
Electro-optical properties of an orthoconic liquid crystal mixture (W-182) and its molecular dynamics
}

\author{
P. Nayek, ${ }^{1}$ S. Kundu, ${ }^{1}$ S. K. Roy, ${ }^{1, a)}$ T. Pal Majumder, ${ }^{2}$ N. Bennis, ${ }^{3}$ J. M. Oton, ${ }^{3}$ and \\ R. Dabrowski ${ }^{4}$ \\ ${ }^{1}$ Department of Spectroscopy, Indian Association for the Cultivation of Science, Jadavpur, Calcutta 700032, \\ India \\ ${ }^{2}$ Department of Physics, University of Kalyani, Kalyani 741235, West Bengal, India \\ ${ }^{3}$ Department of Technologia Fotonica, ETSI Telecommunication, Universidad Politechnica de Madrid, \\ Ciudad Universitaria, 28040 Madrid, Spain \\ ${ }^{4}$ Institute of Chemistry, Military University of Technology, 00-908 Warsaw, Poland
}

(Received 4 June 2007; accepted 30 December 2007; published online 6 March 2008)

\begin{abstract}
We observed that the perfect dark state problem could be solved by using orthoconic antiferroelectric liquid crystal (OAFLC) instead of normal AFLC by comparing the properties of isocontrast and dispersion chromaticity of W-182 OAFLC and normal AFLC CS-4001. We electro-optically observed that several subphases such as $\mathrm{SmC}_{\gamma}^{*}, \mathrm{SmC}_{\beta}^{*}, \mathrm{SmC}_{\alpha}^{*}$ and antiferroelectric $\operatorname{Sm} I^{*}{ }_{A}$ phases exist in W-182 OAFLC. We dielectrically observed in $4 \mu \mathrm{m}$ thin cell that during heating, several new phases appeared. In the high temperature antiferroelectric region, a higher order than $\mathrm{Sm} C^{*}$ phase could be detected dielectrically, in the temperature range of 91-98 ${ }^{\circ} \mathrm{C}$, behaving similar to $\mathrm{SmC}_{\gamma}{ }^{*}$ and also, another phase below $\mathrm{Sm} C^{*}$ region could be dielectrically detected in the temperature range of $103-1100{ }^{\circ} \mathrm{C}$, behaving similar to $\mathrm{SmC}_{\alpha}{ }^{*}$, and an antiferroelectric, similar to $\mathrm{SmI}_{A}{ }^{*}$ phase, was observed in the lower temperature region of the antiferroelectric phase; those are definitely arising due to surface force and interfacial charges interactions. We observed both $P_{H}$ and $P_{L}$ relaxation modes in both cells, although they differed in their strength and relaxation frequency. We studied extensively our observations of $P_{H}$ and $P_{L}$ modes in the antiferroelectric region, a Goldstone mode in the ferroelectric region and a soft mode in the ferroelectric region and $\mathrm{Sm}^{*}$ phases. (C) 2008 American Institute of Physics. [DOI: $10.1063 / 1.2890127]$
\end{abstract}

\section{INTRODUCTION}

Research in orthoconic antiferroelectric liquid crystals (OAFLCs) has achieved a remarkable potential in recent times, due to the fact that the static dark state problem can be solved by using a surface-stabilized OAFLC material possessing a director tilt $\theta= \pm 45^{\circ}$. Tilts of the molecules in adjacent layers of antiferroelectric smectic $C$ phase $\left(\mathrm{Sm}_{A}{ }^{*}\right)$ are oppositely directed and there is no net polarization. ${ }^{1-8} \mathrm{In}$ antiferroelectric $\mathrm{SmC}_{A}{ }^{*}$ phase, two relaxation modes can be expected, one with a lower frequency region in the order of a few hertz and the other with a higher frequency region. Several research groups have defined both relaxations, though in a different fashion. We have assumed both relaxations as in phase, and the antiphase fluctuation phenomena in our dielectric study are based on several reasons that will be discussed explicitly later. Sometimes, a third relaxation, observed near $1 \mathrm{kHz}$, referred to as Goldstone-like mode, arises due to residual helical superstructure.

Although recent developments of AFLCs in display devices are advancing due to the fact that they have has tristate switching capability, easy dc compensation, microsecond response, hemispherical viewing angle (in-plane switching geometry), intrinsic log gray-scale capability, and no ghost effect, yet the perfect dark state problem is still present in the

\footnotetext{
${ }^{a)}$ Author to whom correspondence should be addressed. Electronic mail: spskr@iacs.res.in.
}

AFLC display. Several research groups have already reported that such perfect dark state problem can be removed by using OAFLC having tilt angle of approximately $45^{\circ} .{ }^{1-8}$ Because of this, the importance of research in OAFLC has made a tremendous progress in recent times. It has also been reported that pretransitional effect and, thus, dynamic light leakage are minimized or even rendered completely absent by using OAFLC molecules.

Several subphases were classified according to the number of layers and their orientation in a unit cell. ${ }^{9}$ These subphases such as $\mathrm{SmC}_{\alpha}{ }^{*}, \mathrm{Sm}_{\beta}{ }^{*}$, and $\mathrm{SmC}_{\gamma}{ }^{*}$ can exhibit polarization between those of antiferroelectric and ferroelectric phases and often have a very complex electro-optic signature. At high temperatures, antiferroelectric nature was observed, though it actually behaves with a ferrielectric nature due to the emergence of the devil's staircase, ${ }^{10}$ and the $\mathrm{SmC}_{\gamma_{*}}^{*}$ phase behaves with a ferrielectric nature. Although $\mathrm{SmC}_{\beta}{ }^{*}$, in most cases, shows a similar behavior to the ferroelectric phase $\left(\mathrm{SmC}^{*}\right),{ }^{9,10}$ the dielectric and the electroclinic measurements indicate that the $\mathrm{SmC}_{\beta}{ }^{*}$ phase is different from the $\mathrm{SmC}^{*}$ phase and is actually ferrielectric in nature. ${ }^{11}$ Recently, Tatemori et al. found that the dielectric behavior of the $\mathrm{SmC}_{\beta}{ }^{*}$ phase is quite different from that of the $\mathrm{Sm} C^{*}$ phase, ${ }^{12}$ the complex dielectric constant exhibiting a twostep decrease with increasing bias field, compared to a onestep decrease for the $\mathrm{SmC}^{*}$ phase. Gleeson et al. recently suggested a model of the $\mathrm{SmC}_{\beta}{ }^{*}$ phase, ${ }^{13}$ where each layer 


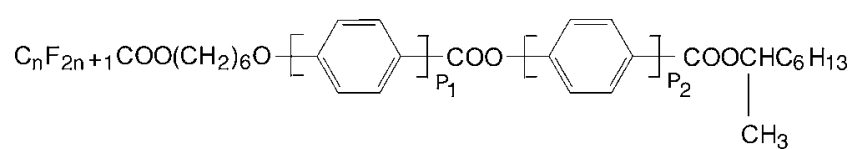

FIG. 1. Chemical formula of a partly fluorinated orthoconic antiferroelectric liquid crystal (OAFLC).

contains an excess of specific conformers and complete phase separation does not occur. It has also been reported that the subphases $\left(\mathrm{SmC}_{\alpha}{ }^{*}, \mathrm{Sm}_{\beta}{ }^{*}\right.$, and $\left.\mathrm{Sm} C_{\gamma}{ }^{*}\right)$ disappear and the synclinic $\mathrm{Sm} C^{*}$ phase emerges, with a decrease in the optical purity, ${ }^{9,13}$ adding more and more amounts of the enantiomer with opposite handedness. In the racemic mixture, only $\mathrm{SmC}^{*}$ and $\mathrm{SmC}_{A}{ }^{*}$ phases exist. It was reported earlier that a highly ordered antiferroelectric phase could exist at a lower temperature region close to the crystal region. Kundu et al. ${ }^{14}$ mentioned that a transition could occur from $\mathrm{SmC}_{A}{ }^{*}$ to $\mathrm{SmI} I_{A}{ }^{*}$ due to the strong coupling of long range bond orientational order and the $c$ director.

In the present work, we have studied the electro-optical properties and the dielectric spectroscopy of an OAFLC. Spontaneous polarization of the sample has also been measured. It was observed experimentally that three more phases appear: one in high temperature antiferroelectric region, another at high temperature ferroelectric region, and a third at lower temperature region of $\mathrm{SmC}_{A}{ }^{*}$ phase for $4 \mu \mathrm{m}$ cell thickness due to surface forces and restricted geometry of accumulated space charges at the interface layers. These may be distinctly observed by dielectric process. We will also discuss the orientation by using dielectric and optical microscopy of OAFLC molecules.

\section{EXPERIMENTAL TECHNIQUES}

The investigated OAFLC sample, having the code name W-182, was synthesized by Dabrowski and co-workers ${ }^{3,4}$ by using partly fluorinated compounds of a common formula, as given below in Fig. 1. The phase sequence of the sample is given as below, 3,4

$$
\begin{aligned}
\mathrm{Cr}< & -23 \mathrm{Sm}_{A}{ }^{*} 98.9-99.6 \mathrm{Sm}^{*} 114.9 \\
& -115.5 \mathrm{Sm} A 120-122.2 \text { Iso. }
\end{aligned}
$$

The indium tin oxide (ITO) coated planar aligned EHC glass cells with thickness of $4 \mu \mathrm{m}$ were used for dielectric, optical, and electro-optic study. The effective area of the cell was $16 \mathrm{~mm}^{2}$. The cells were first heated up to a temperature of a few degrees higher than $100{ }^{\circ} \mathrm{C}$ and kept there for half an hour so that any moisture is completely removed. The temperature of the cells was controlled by a Mettler FP5 temperature controller attached to a Mettler FP52 heat chamber. The cell was filled with the sample at its isotropic temperature and then was gradually cooled, at the rate of $1{ }^{\circ} \mathrm{C} / \mathrm{min}$. Dielectric data were recorded using a HP 4192A impedance analyzer and controlled by the computer in a frequency range of $10 \mathrm{~Hz}-13 \mathrm{MHz}$ with different temperatures. Since the dielectric loss spectra of the sample have a comparatively high dc loss at the low frequency side and it is also asymmetric, the frequency dependence of the complex dielectric permittivity $\varepsilon^{*}$ can be better described by the superposition of
Havriliak-Negami ${ }^{15}(\mathrm{H}-\mathrm{N})$ fit function and a conductivity contribution. The characteristic dielectric parameters, such as dielectric strength and relaxation frequency, were extracted after fitting the dielectric data in the following HavriliakNegami function: ${ }^{15}$

$$
\varepsilon^{\prime \prime}=\frac{\sigma_{0}}{\varepsilon_{0}} \frac{1}{\omega^{s}}+\sum_{k=1}^{N} \operatorname{Im}\left\{\frac{\Delta \varepsilon_{k}}{\left[1+\left(i \omega \tau_{k}\right)^{\alpha_{k}}\right]^{\beta_{k}}}\right\},
$$

with the dielectric strength $\Delta \varepsilon_{k}$ and the relaxation time $\tau_{k}$ for each individual process $k$ involved in the dielectric relaxation, the vacuum permittivity $\varepsilon_{0}(8.854 \mathrm{pF} / \mathrm{m})$, and the conduction parameter $\sigma_{0}$. The exponents $\alpha$ and $\beta$ are empirical fit parameters, which describe a symmetric and nonsymmetric broadening, respectively, of the relaxation peaks. Because of strong cross-correlation effects existing in this sample, Eq. (1) represents the quantitative estimation of relaxation times or frequency and the dielectric strength of all existing relaxations. Since the molecules in our study possess comparatively high dc conductivity, the dc loss was added to the H-N equation (1). The real part of the permittivity is not affected by the dc conductivity. We have used this fact to prove the correctness of the conductivity correction by applying the Kramers-Krönig relation. The fit of the spectra could be performed with multiple relaxation processes. The first term on the right-hand side of Eq. (1) describes the motion of free charge carriers in the sample. In the case of an Ohmic behavior $(s=1), \sigma_{0}$ is the Ohmic conductivity of the smectic material.

For electro-optic measurement, a HP 33120A signal generator and a HP 54603B oscilloscope were used. The spontaneous polarization and the relaxation time were measured by polarization reversal method. The mathematical relation used to calculate the value of spontaneous polarization is given below,

$$
P s=(1 / 2 A) \int i(t) d t
$$

All measurements were computer based.

\section{RESULTS AND DISCUSSION}

Isocontrast and dispersion chromaticity were measured by using the equipment called EZ contrast for antiferroelectric liquid crystals CS-4001 and OAFLC W-182. The light source was based on a $125 \mathrm{~W}$ arc lamp; illumination intensity was set on the sample from 10 to 10000 lux (diffuse). The spectral composition of the light was adjusted by adding color glass filters. Light was guided from the illumination lamp to the diffuser by means of optical fiber bundles. The diffuser was fixed on the side of our EZ-contrast equipment. Figures 2(a) and 2(b) shows the calculated viewing angle properties of the CS-4001 and W-182 films, respectively, at $550 \mathrm{~nm}$. Comparing the figures of isocontrast [Figs. 2(a) and 2(b)] of W-182 mixture with CS-4001, it is observed that the viewing angle measured in the cell filled with CS-4001 is wider, but in the cell filled with W-182, it shows a higher contrast with a low viewing angle [Fig. 2(b)]. The configuration for W-182 [Fig. 2(b)] can provide an excellent dark state in comparison with CS-4001 [Fig. 2(a)]. ${ }^{16,17}$ Since op- 

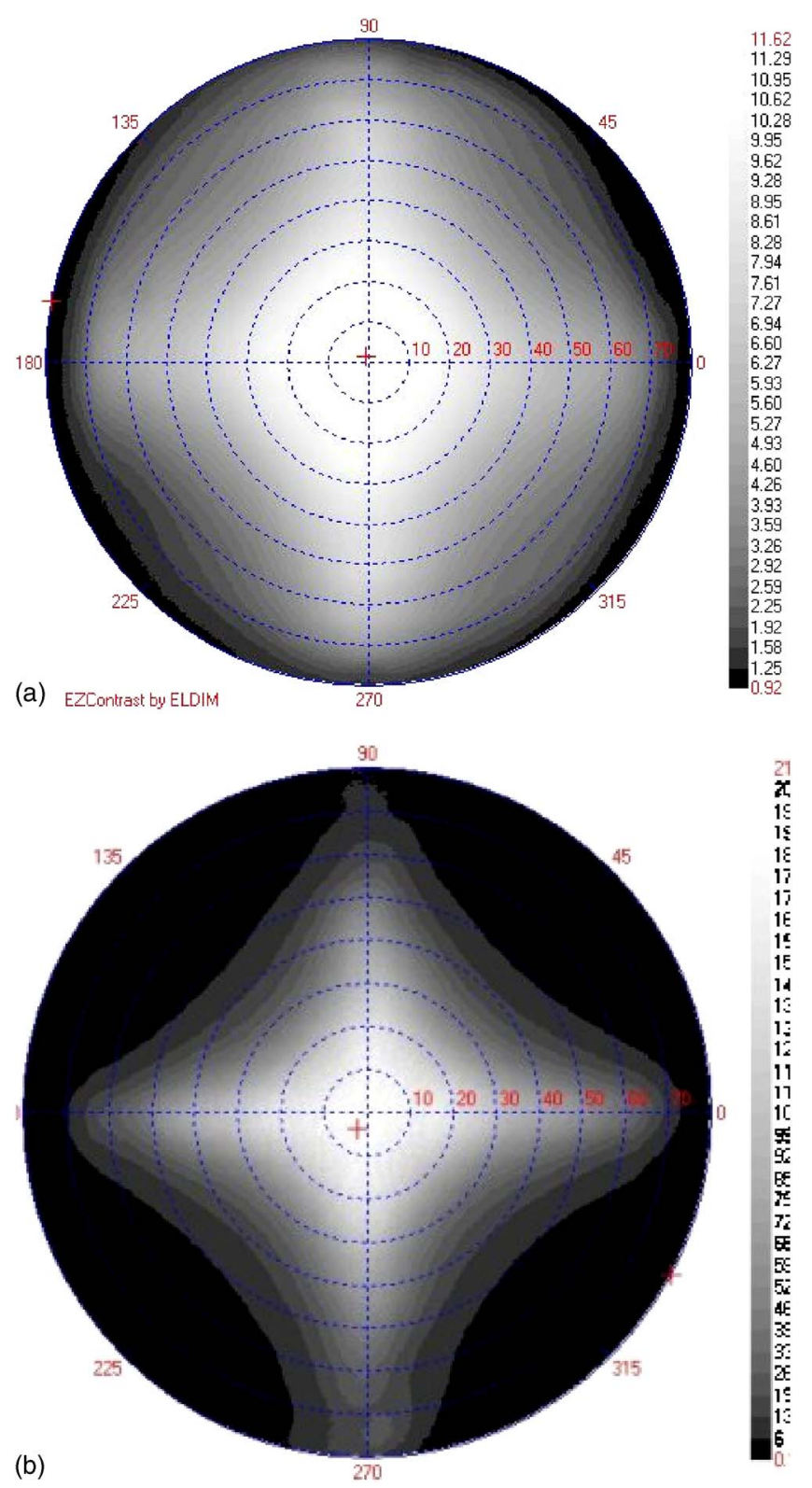

FIG. 2. (Color online) (a) Isocontrast plot measured with an ELDIM EZcontrast system on the cell filled with CS-4001. (b) Isocontrast plot measured with an ELDIM EZ-contrast system on the cell filled with W-182.

tical performance is strongly dependent on the optical property in the dark state or a good dark state is essential for good contrast performance, therefore, an improvement in the optical viewing angle achieved for W-182 [Fig. 2(b)] in comparison with CS-4001 was observed [Fig. 2(a)]. By using the same equipment, we measured the color coordinate using glass color filters designed specifically for each chargecoupled device to closely match the Commission Internationale l'Eclairge (CIE) 1931. The CIE defined in 1931, another basis in terms of (virtual) primaries $X$ (the luminousefficiency function), $Y$, and $Z$, allows it to match all visible colors as linear combinations with positive coefficients only, i.e., the so-called chromaticity values $X, Y$, and $Z$, and any visible color can be expressed as $C=X X+Y Y+Z Z$. Normalization to $X+Y+Z=1$ gives new coordinates $u, v$, and $w=1$ $-u-v$, and these are independent of luminous energy $X+Y$
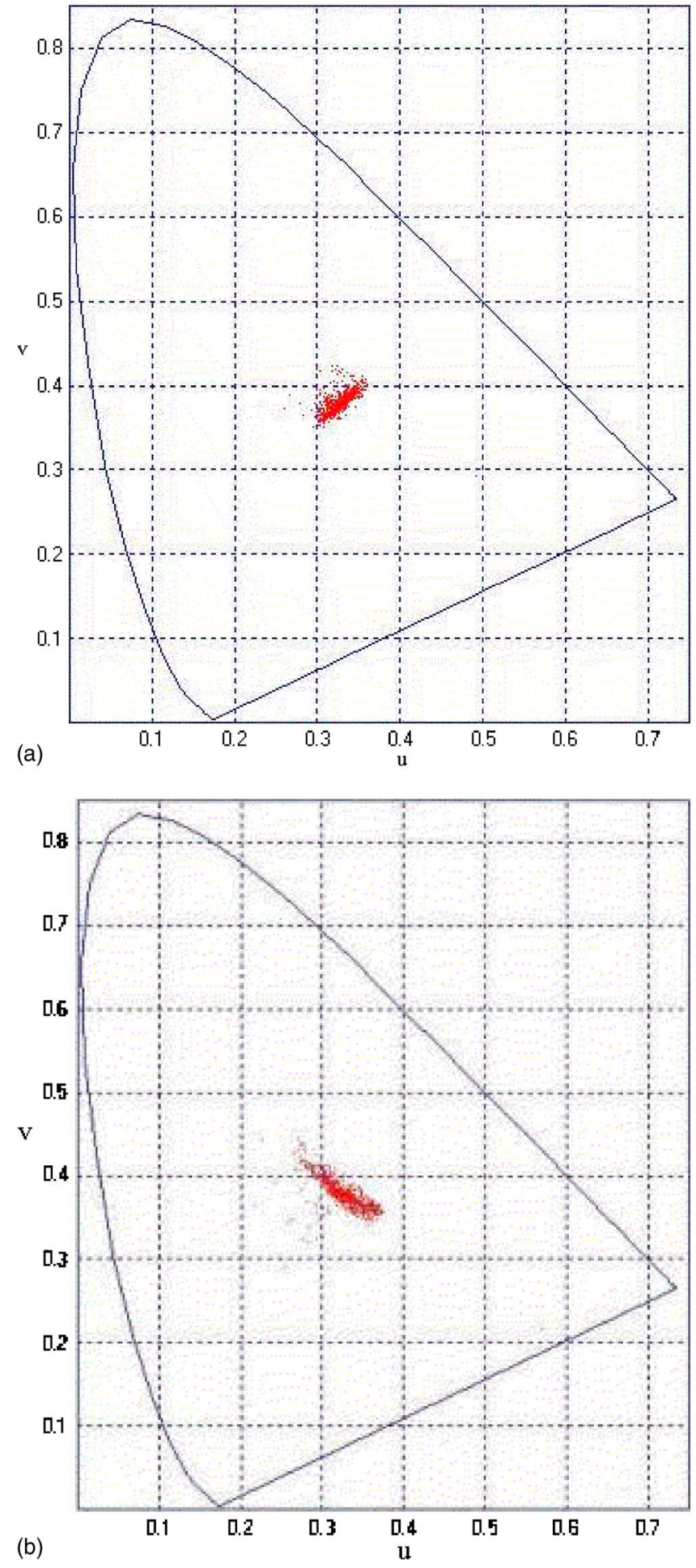

FIG. 3. (Color online) (a) CIE chromaticity diagram measured on cells filled with CS-4001 in $x y$ color dispersion in 1931 system. The variation of normalized chromaticity $(v)$ along the $y$ axis with other normalized chromaticity $(u)$ along the $x$ axis. (b) CIE chromaticity diagram measured on cells filled with W-182 in $x y$ color dispersion in 1931 system. The variation of normalized chromaticity $(v)$ along the $y$ axis with other normalized chromaticity $(u)$ along the $x$ axis.

$+Z$. Standard white light is located at a point near $u=v$ $=1 / 3$. Figures $3(\mathrm{a})$ and $3(\mathrm{~b})$ show the dispersion chromaticity for CS-4001 and W-182 samples, respectively. In comparison with the dispersion chromaticity of both samples [Figs. 3(a) and 3(b)], it was observed that no significant color 


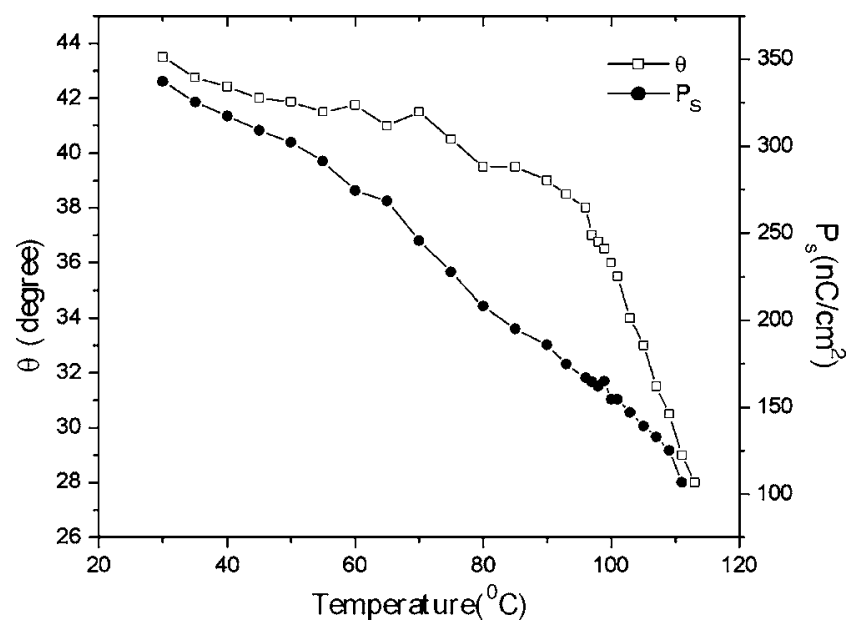

FIG. 4. The variation of tilt angle $(\theta)$ and the spontaneous polarization $\left(P_{S}\right)$ of W-182 OAFLC molecules with temperature for $4 \mu \mathrm{m}$ cell thickness.

dispersion was achieved for CS-4001 filled cell, but a small deviation of white light toward the green color for W-182 filled cell was noticed. ${ }^{18}$

Both the tilt angle $(\theta)$ and the spontaneous polarization $\left(P_{S}\right)$ were measured by using $4 \mu \mathrm{m}$ cell filled with $\mathrm{W}-182$ orthoconic mixtures. For the measurement of tilt during heating, an ac voltage of $30 V_{\mathrm{PP}}$ with $100 \mathrm{mHz}$ frequency was used and for $P_{S}$ measurement, $60 V_{\mathrm{PP}}$ with $10 \mathrm{~Hz}$ frequency was used as an input signal, employing a FLC Electronics voltage amplifier F10A and HP33120A signal generator.

At room temperature $\left(30^{\circ} \mathrm{C}\right)$, we measured the tilt angle $\theta \approx 43.5^{\circ}$ (Fig. 4). The tilt decreased slowly with temperature increase of up to $80^{\circ} \mathrm{C}$ with $\theta \approx 40^{\circ}$. After $80^{\circ} \mathrm{C}$, the tilt decreased by a step up to $93{ }^{\circ} \mathrm{C}$ to reach $\theta \approx 39^{\circ}$, at which point the tilt angle decreased sharply with temperature increase and reached $\theta \approx 28^{\circ}$ at $116^{\circ} \mathrm{C}$. It indicates that the three regions could be recognized, revealing the existence of the three phases.

Spontaneous polarization $\left(P_{S}\right)$ rapidly decreased with temperature, but it is also indicated that the three regions are similar in tilt angle (Fig. 4). The value of $P_{S}$ is comparatively higher than that of normal AFLCs and it is of the order of $300 \mathrm{nC} / \mathrm{cm}^{2}$ at $40^{\circ} \mathrm{C}$, which must closely correspond to the results earlier reported by other researchers for different OAFLCs, ${ }^{1-8}$ since those molecules possess a high tilt and a higher order. This is one of the most important physical advantages over normal AFLC.

It was observed clearly that from $30^{\circ} \mathrm{C}$ [Fig. 5(a)] up to $50{ }^{\circ} \mathrm{C}$ a single current peak, and after $50{ }^{\circ} \mathrm{C}$, double polarization peaks appear [Fig. 5(b)]. Such single polarization peak phenomenon from 30 to $50{ }^{\circ} \mathrm{C}$ comes from a highly ordered monotropic $\mathrm{SmI}_{A}{ }^{*}$ phase, ${ }^{14,19,20}$ but after $50^{\circ} \mathrm{C}$, double polarization peaks arise due to the existence of $\mathrm{SmC}_{A}{ }^{*}$ phase, which is observed in the temperature range from 50 to $90{ }^{\circ} \mathrm{C}$ [Figs. 5(b) and 5(c)]. From 90 to $111^{\circ} \mathrm{C}$, triple polarization peaks [Figs. 5(d)-5(f)] were observed, indicating the existence of a $\mathrm{Sm} C^{*}$-like ferrielectric phase ${ }^{19-23}$ or may be the mixture of ferroelectric and ferrielectric phases in such a temperature region. It may be considered that the highest peak arises due to the reversal of the ferroelectric

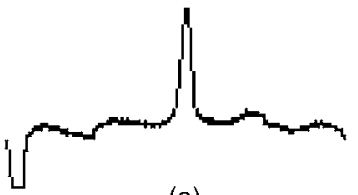

(a)
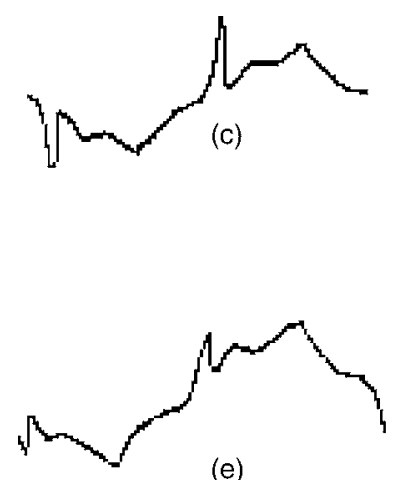

(e)

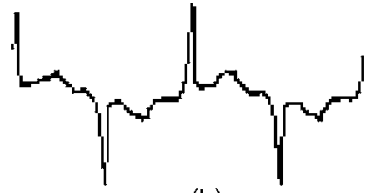

(b)

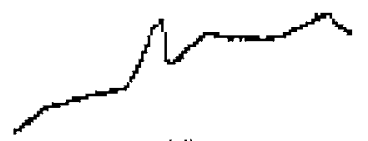

(d)

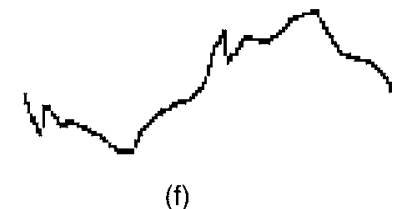

(f)
FIG. 5. The polarization response current peaks obtained at different temperatures during heating of the studied OAFLC for $4 \mu \mathrm{m}$ cell thickness: (a) 30, (b) 55 , (c) 80 , (d) 100 , (e) 105 , and (f) $109^{\circ} \mathrm{C}$.

spontaneous polarization. The other two peaks, which appeared, clearly indicate that the phase is antiferroelectric in the temperature range from 50 to $90{ }^{\circ} \mathrm{C}$. The three peak region, which appeared in the temperature range from 90 to $111^{\circ} \mathrm{C}$, is a characteristic feature of ferrielectricity. So, we can assert that ferrielectric subphases such as $\mathrm{SmC}_{\gamma}^{*}$, $\mathrm{SmC}_{\beta}^{*}$, and $\mathrm{SmC}_{\alpha}^{*}$ phases appear in the abovementioned temperature region, due mainly to the surface anchoring force, and the interactions are due to generated ions in each interfacing layer.

A thermally activated loss process has been observed at the low frequency region of the conductivity wing, and the other relaxation process lies as a hump in the dielectric loss curve. We observed a high dc conductive loss on the low frequency side of the dielectric loss spectra in all cases for dielectric measurement, especially at the high temperature region that we had already reported in our earlier paper. ${ }^{24}$ In this case, the molecules are highly polar having fluorine so that the dc conductivity is comparatively very high throughout the region of investigation. With $\mathrm{H}-\mathrm{N}$ fitting function from Eq. (1), we find four distinct relaxation phenomena designated as modes I, IA, II, and III, except absorption for the ITO mode and (Maxwell-Wagner-Sillars) MWS mode, including $\mathrm{dc}$ conductivity for the heating process in $4 \mu \mathrm{m}$. We observed mode I from 30 to $44{ }^{\circ} \mathrm{C}$, and the strength roughly became constant and its relaxation frequency became weakly dependent on temperature. That relaxation is not related to any collective motion and both their strength and relaxation frequency indicate a noncollective dynamics (Figs. 6 and 7). We refer to such relaxation as molecular relaxation, a noncollective phenomenon. We observed a mode having comparatively high dielectric strength at the low frequency region and distinctly observed it at approximately $98^{\circ} \mathrm{C}$ and shows up to $120^{\circ} \mathrm{C}$, until our measured highest temperature. Since such mode is well separated from 


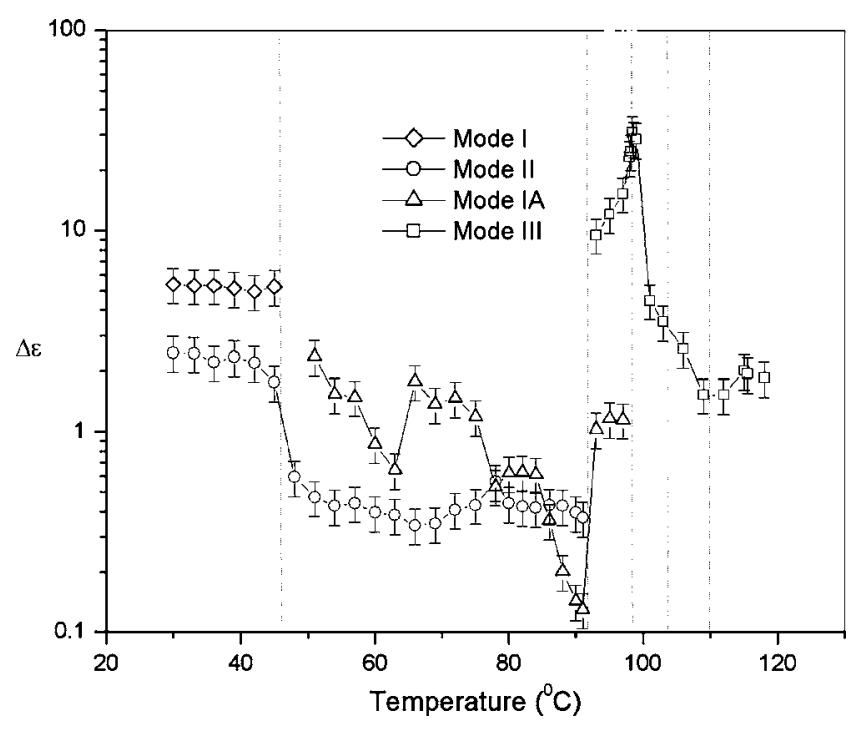

FIG. 6. The variation of dielectric strength $(\Delta \varepsilon)$ with temperature for $4 \mu \mathrm{m}$ cell thickness during heating.

other relaxation phenomena and because it possesses a high strength, it can be referred to as MWS relaxation, ${ }^{24}$ which was also reported in our earlier works. Such MWS mode is a thermally activated process observed in the lower frequency region throughout the temperature studied. Such a mode arises at conductivity wing and this process has much dielectric strength and is almost independent of temperature. MWS occurred due to the charge accumulation at the layer-to-layer interface and it is distinguishable from other relaxation phenomena by its larger intensity. We already discussed about the existence of such relaxation phenomena and their effect on the total relaxation dynamics throughout the temperature studied in our earlier report. We are leaving further discussion of MWS relaxation in this report. ${ }^{24}$

The dielectric spectrum in the temperature range from 50 to $91{ }^{\circ} \mathrm{C}$ shows two absorption peaks, modes IA and II, well separated from each other by both strength and relaxation frequency of the order of approximately $10 \mathrm{kHz}$ and more (Figs. 6 and 7). Mode IA has a higher dielectric

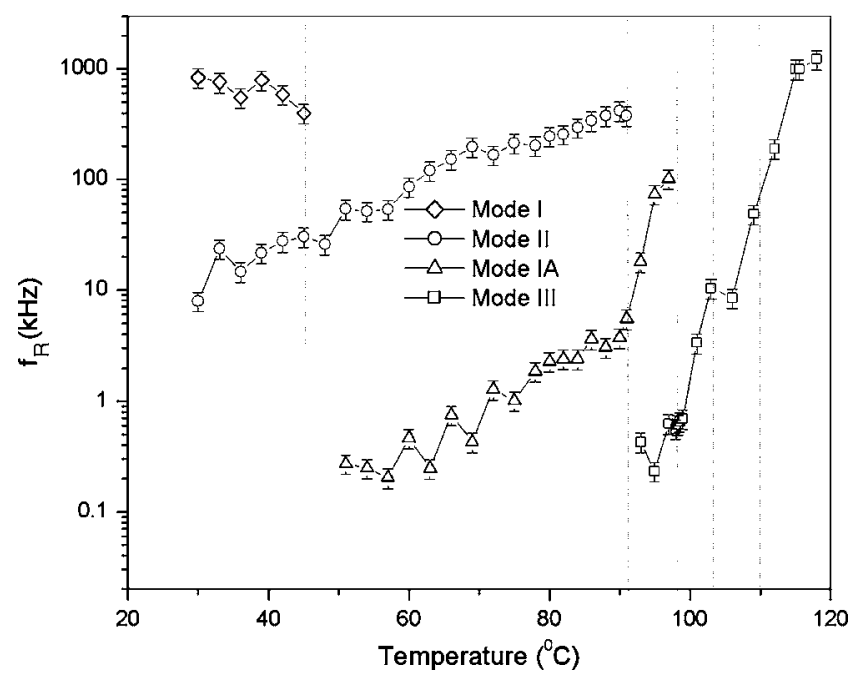

FIG. 7. The variation of relaxation frequency $\left(f_{R}\right)$ with temperature for $4 \mu \mathrm{m}$ cell thickness during heating. strength and decreases slowly with an increase of temperature and then sharply falls at $91{ }^{\circ} \mathrm{C}$ to attain a minimum value of approximately 0.15 . Mode II slowly decreases to the minimum value of 0.35 at $91{ }^{\circ} \mathrm{C}$. Modes IA and II can be assigned as $P_{L}$, in phase motion of antitilt pairs, and $P_{H}$, antiphase motion of antitilt pairs, respectively. Several groups have proposed the existence of both relaxations in antiferroelectric phase; although they individually explain that such two modes are based on different originations, no definite unique origin of such modes exist. ${ }^{25-30}$ Buivydas et al. finally proposed the origin of $P_{L}$ and $P_{H}$ modes as arising due to a collective reorientation of the molecules around the cones in the same direction, i.e., in phase motion in $\phi$ variable (azimuthal angle) in antitilt pairs, and $P_{H}$ mode arises due to the collective reorientation of the molecules around the cones in the opposite direction and antiphase motion in azimuthal angle in their antitilt position. The Buivydas model for the explanation of $P_{L}$ and $P_{H}$ modes until now has been satisfactorily accepted and it is satisfactory enough to explain the origination of the existence of such relaxation in antiferroelectric phase. However, until now, no such definite reasons for the origination behind $P_{L}$ and $P_{H}$ modes in antiferroelectric phase have been considered. Mode III was observed from approximately $92{ }^{\circ} \mathrm{C}$ and shows up to $121^{\circ} \mathrm{C}$ and such a mode can be divided into groups such as a Goldstone-like mode from 92 to $98{ }^{\circ} \mathrm{C}$, Goldstone mode from 98 to $110^{\circ} \mathrm{C}$, and soft mode from 110 to $121{ }^{\circ} \mathrm{C}$ (Figs. 6 and 7). The H-N fitted relaxation frequency for mode II is $67.3 \mathrm{~Hz}$ at $98.6^{\circ} \mathrm{C}$ and increases sharply with the increase of temperature. The $\mathrm{H}-\mathrm{N}$ fitted relaxation frequency of mode III is $5305 \mathrm{kHz}$ at $51{ }^{\circ} \mathrm{C}$ and remains approximately constant with an increase in temperature from $51^{\circ} \mathrm{C}$. The dielectric strength of mode III decreases with an increase in temperature and it is observed up to $106^{\circ} \mathrm{C}$, and the relaxation phenomena is referred to as Goldstone mode in the temperature region from 98 to $106{ }^{\circ} \mathrm{C}$. Mode III in the temperature range from 110 to $120^{\circ} \mathrm{C}$ is referred to as soft mode because the dielectric strength increases with an increase in temperature from 110 to $115^{\circ} \mathrm{C}$ and then decreases with an increase in temperature up to $120^{\circ} \mathrm{C}$. The corresponding relaxation frequency of mode III in that region sharply increases with an increase in temperature and finally, it becomes saturated. Modes IA and II are referred to as $P_{H}$ and $P_{L}$ modes, respectively. ${ }^{25-30}$ Mode II $\left(P_{H}\right.$ mode) can be observed from room temperature to $98{ }^{\circ} \mathrm{C}$ and mode IA $\left(P_{L}\right.$ mode $)$ can be observed from 50 to $91^{\circ} \mathrm{C}$.

The observed Goldstone mode in the temperature range from 98 to $110^{\circ} \mathrm{C}$ (mode III) shows that its relaxation frequency strongly depends on temperature (Fig. 7). The relaxation frequency sharply increases with an increase in temperature, which is generally observed for the helix distortion of ferroelectric smectics. In the temperature range from 92 to $98^{\circ} \mathrm{C}$, the observed Goldstone-like mode (mode III) dielectric strength increases sharply with an increase in temperature and reaches a maximum (Fig. 6). Such a phase may be identical to the $\mathrm{SmC}_{\gamma}{ }^{*}$ phase because the strength of mode III increases sharply with temperature and shows three peaks in the polarization spectra. 
The relaxation frequency $\left(f_{R}\right)$ of a linear motion is related to the activation energy $\left(E_{A}\right)$ by the following Arrhenius law as given below:

$$
f_{R}=A \exp \left(-E_{A} / k_{B} T\right)
$$

where $E_{A}$ stands for activation energy that is associated with a particular molecular motion and $k_{B}$ is the well-known Boltzman's constant. The observed soft mode relaxation in the temperature region from 110 to $120{ }^{\circ} \mathrm{C}$ roughly obeys the Curie-Weiss law; i.e., its relaxation frequency obeys $f_{S}$ $\sim \mathrm{A} \exp \left(-E_{A} / K_{B} T\right)$, similar to Arrhenius law as given in Eq. (3) (Fig. 7) and its strength obeys $\Delta \varepsilon_{S} \sim A \exp \left(E_{A} / K_{B} T\right)$ (Fig. 6). The region from 103 to $110^{\circ} \mathrm{C}$ may be referred to as $\mathrm{SmC}{ }_{\alpha}^{*}$ phase because it shows the Goldstone relaxation in such a region with comparatively low strength in comparison with the ferroelectric Goldstone mode (Fig. 6) and also shows three peaks in the polarization spectra (Fig. 5). The region from 98 to $103{ }^{\circ} \mathrm{C}$ is purely ferroelectric in character by dielectric process because it obeys the usual behavior of the Goldstone mode similar to the ferroelectric $\mathrm{Sm} C^{*}$ phase.

The high frequency relaxation $P_{H}$ mode exists from room temperature $\left(30{ }^{\circ} \mathrm{C}\right)$ having a relaxation frequency of approximately $10 \mathrm{kHz}$ at room temperature and increases sharply with temperature. Such a relaxation exists up to the temperature just a few degrees below that of the $\mathrm{SmC}{ }_{\gamma}{ }^{*}-\mathrm{Sm} C^{*}$ transition point. It clearly indicates that the high frequency relaxation, $f_{H} \sim A \exp \left(-E_{A} / K_{B} T\right)$, obeys the Arrhenius law [Eq. (3)]. It also clearly indicates the fact that the dielectric strength (Fig. 6) for $P_{H}$ mode obeys the soft mode behavior if we consider a transition point at $45^{\circ} \mathrm{C}$ and its corresponding relaxation frequency (Fig. 7) has also a high value. Such relaxation frequency (Fig. 7) obeys the Arrhenius law [Eq. (3)] as we mentioned earlier, where the tilt angle in the region from $43.5^{\circ}$ to $42^{\circ}$ (Fig. 4) in the temperature range from room temperature $\left(30^{\circ} \mathrm{C}\right)$ to $45^{\circ} \mathrm{C}$ is taken roughly as temperature independent. The dielectric constant variation for $10 \mathrm{kHz}$ (high frequency) also indicates that a transition may occur at $45{ }^{\circ} \mathrm{C}$. The calculated activation energy for mode I (noncollective motion) observed only in assigned $\mathrm{SmI}_{A}{ }^{*}$ phase fitted with Arrhenius law [Eq. (3)] is $-3.24 \mathrm{kCal} \mathrm{mol}^{-1} \mathrm{~K}^{-1}$ in the temperature range from 30 to $45^{\circ} \mathrm{C}$. Such activation energy for the IA mode $\left(P_{L}\right.$ mode) is $50.46 \mathrm{kCal} \mathrm{mol}^{-1} \mathrm{~K}^{-1}$ in the temperature range from 51 to $91{ }^{\circ} \mathrm{C}$, activation energy for mode II $\left(P_{H}\right.$ mode $)$ is $5.84 \mathrm{kCal} \mathrm{mol}^{-1} \mathrm{~K}^{-1}$ in the temperature range from 30 to $95^{\circ} \mathrm{C}$, activation energy for mode III is $58.5 \mathrm{kCal} \mathrm{mol}^{-1} \mathrm{~K}^{-1}$ in the temperature range from 106 to $115^{\circ} \mathrm{C}$, and activation energy for mode III (soft mode) is $9.66 \mathrm{kCal} \mathrm{mol}^{-1} \mathrm{~K}^{-}$in the temperature region from 115 to $118{ }^{\circ} \mathrm{C}\left(\mathrm{Sm} A^{*}\right.$ region$)$.

\section{CONCLUSIONS}

It was clearly indicated that the improvement of optical viewing angle was achieved for W-182 OAFLC with respect to normal AFLC molecules, CS-4001, by comparing their isocontrast characteristics. With the help of isocontrast and dispersion chromaticity of both molecules, the dark state problem in display devices can be improved by using OAFLC.

Electro-optically, we found the existence of several subphases for $4 \mu \mathrm{m}$ cell during heating and that was strongly supported by dielectric measurement under such geometry. By using electro-optical studies of such molecules, a highly ordered monotropic $\mathrm{Sm} I^{*}$ phase in the lower temperature side of antiferroelectric region, several ferrielectric subphases, or mixtures of ferroelectric and ferrielectric phases were found to exist on the higher temperature side of the antiferroelectric region. By comparing the electro-optic signature and dielectric variation at different temperatures, along with other references, we designated the subphases as $\mathrm{SmI}_{A}{ }^{*}, \mathrm{Sm}_{\gamma}{ }^{*}, \mathrm{Sm} C^{*}$-like, and $\mathrm{Sm}_{\alpha}{ }^{*}$. Apart from the ITO mode and MWS relaxation, we observed several relaxations such as $P_{L}$ mode, $P_{H}$ mode, Goldstone-like mode, Goldstone mode, and soft mode in W-182 OAFLC in $4 \mu \mathrm{m}$ cell during heating.

${ }^{1}$ G. Scalia, P. Rudquist, D. S. Hermann, K. D'Have, S. T. Lagerwall, and J. R. Sambles, J. Appl. Phys. 91, 9667 (2002).

${ }^{2}$ P. Rudquist, J. P. F. Lagerwall, J. G. Meier, K. D'Have, and S. T. Lagerwall, Phys. Rev. E 66, 061708 (2002).

${ }^{3}$ S. J. Klosowicz, W. Piecek, R. Dabrowski, and P. Perkowski, Mol. Cryst. Liq. Cryst. 422, 21 (2004).

${ }^{4}$ N. Bennis, R. Dabrowski, A. Spadlo, P. Kula, X. Quintana, and J. M. Oton, Mol. Cryst. Liq. Cryst. 422, 37 (2004).

${ }^{5}$ K. D'Have, P. Rudquist, S. T. Lagerwall, H. Pauwels, W. Drzewinski, and R. Dabrowski, Appl. Phys. Lett. 76, 3528 (2000).

${ }^{6}$ K. D’Have, A. Dahlgren, P. Rudquist, J. P. F. Lagerwall, G. Anderson, M. Matuszczyk, S. T. Lagerwall, R. Dabrowski, and W. Drzewinski, Ferroelectrics 244, 115 (2000).

${ }^{7}$ K. D'Have, Per. Rudquist, M. Matuszczyk, S. T. Lagerwall, H. Pauwels, and R. Dabrowski, Proc. SPIE 3955, 33 (2000).

${ }^{8}$ S. T. Lagerwall, A. Dahlgren, P. Jagemalm, P. Rudquist, K. D’Have, H. Pauwels, R. Dabrowski, and W. Drzewinski, Adv. Funct. Mater. 11, 87 (2001).

${ }^{9}$ K. Itoh, M. Kabe, K. Miyachi, Y. Takanishi, K. Ishikawa, H. Takezoe, and A. Fukuda, J. Mater. Chem. 7, 407 (1997).

${ }^{10}$ Y. Takanishi, K. Hiraoka, V. K. Agrawal, H. Takezoe, A. Fukuda, and M. Matsushita, Jpn. J. Appl. Phys., Part 1 30, 2023 (1991).

${ }^{11}$ T. Sako, Y. Kimura, R. Hayakawa, N. Okabe, and Y. Suzuki, Jpn. J. Appl. Phys., Part 2 35, L114 (1996).

${ }^{12}$ S. Tatemori, H. Uhera, J. Hatano, S. Saito, H. Saito, and E. Okabe, Ferroelectrics 244, 241 (2000).

${ }^{13}$ H. F. Gleeson, L. Baylis, W. K. Robinson, J. T. Mills, J. W. Goodby, A. Seed, M. Hird, P. Styring, C. Rosenblatt, and S. Zhang, Liq. Cryst. 26, 1415 (1999).

${ }^{14}$ S. Kundu, T. Ray, and S. K. Roy, Liq. Cryst. 30, 1 (2003).

${ }^{15}$ S. Havriliak and S. Negami, J. Polym. Sci., Part C: Polym. Symp. 14, 99 (1966).

${ }^{16}$ C. D. Hoke, H. Mori, and P. J. Bos, Jpn. J. Appl. Phys., Part 2 38, L642 (1999).

${ }^{17}$ S.-C. A. Lien, C. Cai, R. W. Nunes, R. A. John, E. A. Galligan, E. Colgan, and J. S. Wilson, Jpn. J. Appl. Phys., Part 2 37, L597 (1998).

${ }^{18}$ T. Takahashi, H. Furue, M. Shikada, N. Matsuda, T. Miyama, and S. Kobayashi, Jpn. J. Appl. Phys., Part 2 38, L534 (1999).

${ }^{19}$ A. Fafara, B. Gestblom, S. Wrobel, R. Dabrowski, W. Drzewinski, D. Kilian, and W. Haase, Ferroelectrics 212, 79 (1998).

${ }^{20}$ D. Kilian, S. Hiller, W. Haase, J. M. Hollidt, and G. Heppe, Ferroelectrics 180, 137 (1996).

${ }^{21}$ R. Douali, C. Legrand, and H. T. Nguyen, Ferroelectrics 245, 101 (2000).

${ }^{22}$ R. Douali, C. Legrand, V. Faye, and H. T. Nguyen, Mol. Cryst. Liq. Cryst. Sci. Technol., Sect. A 328, 209 (1999).

${ }^{23}$ M. Wojciechowski, L. A. Gromiec, and G. W. Bak, J. Mol. Liq. 124, 7 (2006).

${ }^{24}$ T. Ray, S. Kundu, T. P. Majumder, S. K. Roy, and R. Dabrowski, J. Mol. Liq. 139, 35 (2008). 
${ }^{25}$ T. Fujikawa, H. Orihara, Y. Ishibashi, Y. Yamada, N. Yamamoto, K. Mori, K. Nakamura, Y. Suzuki, T. Hagiwara, and I. Kawamura, Jpn. J. Appl. Phys., Part 1 30, 2826 (1991).

${ }^{26}$ H. Moritake, Y. Uchiyama, K. Myojin, M. Ozaki, and K. Yoshino, Ferroelectrics 147, 53 (1993).

${ }^{27}$ H. Uehara, Y. Hanakai, J. Hatano, S. Saito, and K. Murashiro, Jpn. J. Appl.
Phys., Part 1 34, 5424 (1995).

${ }^{28}$ K. Hiraoka, H. Takezoe, and A. Fukuda, Ferroelectrics 147, 13 (1993).

${ }^{29}$ J. Hatano, Y. Hanakai, H. Furue, H. Uehara, S. Saito, and K. Murashiro, Jpn. J. Appl. Phys., Part 1 33, 5498 (1994).

${ }^{30}$ M. Buivydas, F. Gouda, S. T. Lagerwall, and B. Stebler, Liq. Cryst. 18, 879 (1995). 